Int. J. Odontostomat.,

5(3):304-308, 2011.

\title{
Sinonasal Mucoepidermoid Carcinoma: a Case Report and Literature Review
}

\author{
Carcinoma Mucoepidermoide Nasosinusal: Reporte de Caso y Revisión de la Literatura
}

Ilson Sepúlveda*; Loreto Spencer ${ }^{* *} \&$ Enrique Platin ${ }^{* * *}$

SEPÚLVEDA, I.; SPENCER, L. \& PLATIN, E. Sinonasal Mucoepidermoid Carcinoma: a case report and literature review. Int. J. Odontostomat., 5(3):304-308, 2011.

SUMMARY: We report on a patient who presented at our clinic with a growth of the right palate of twenty years duration. A biopsy of the area was performed and the lesion was diagnosed as low-grade mucoepidermoid carcinoma (MEC). Due to the size of the tumor, it was decided to begin treatment with radiotherapy followed by chemotherapy. Once the initial treatment was completed, the lesion was reevaluated and surgery followed by reconstruction was recommended. The Patient rejected the recommended treatment and opted to enrolled in a pain management, palliative care program. sinonasal.

KEY WORDS: mucoepidermoid, carcinoma, Computed tomography, Magnetic resonance imaging, tumor

\section{INTRODUCTION}

Malignant neoplasms of the salivary glands are very rare, representing $0.3 \%$ of head and neck malignant tumors (Ghosh-Laskar et al., 2011). Mucoepidermoid Carcinoma (MEC) is the most common malignancy of salivary gland tumors, occurring most frequently in the major salivary glands, predominantly the parotid gland (Giger et al., 2005).

Stewart, Foote and Becker in 1945 first described the histological features of MEC. They reported on 45 salivary gland tumor cases, made up of mucosecretory cell, squamous cells and basal cells or intermediate stratum cells. (Gallager et al., 1959). After comparing the morphological features of MEC with other chronic inflammatory non-neoplastic lesions of the salivary glands it was theorized that these cells originated in the ductal system (Foschini et al., 2002).

MEC usually occurs in the head and neck region but it has been reported in other anatomical regions; for example, distant glandular structures and unlikely sites such as the anal region, esophagus and tracheobronchial mucosa. The latter is extremely rare, corresponding to only $0.1-0.2 \%$ of malignant lung lesions. The lesions often present radiographically as a solitary nodule or mass with or without post obstructive pneumonia or atelectasis (Gallager et al.; Magliulo \& Appiani, 2010; Kim et al., 1999).

Occurrence of MEC in other areas of the head and neck such as the thyroid gland is extremely rare. It is predominant in females and presents as two entities: Typical MEC and Sclerotic MEC with Eosinophilia. Cases of MEC have been reported in the middle ear and mastoid region, where the presence of salivary gland tissues is deemed controversial. Only 5 cases of parotid MEC have been reported in the main excretory duct, where they can be easily confused with minor salivary glands of the oral mucosa or accessory parotid gland (Giger et al., 2005; Davies et al., 2005; Gupta \& Kaluskar, 2003).

Histologically, the proportion of the 3 cellular types helps to define and grade the tumor. High-grade tumors are poorly differentiated, and consist predominantly of intermediate and squamous cells with

\footnotetext{
Oral, Maxillofacial-Head and Neck Radiologist. Department of Ear; Head and Neck Cancer Committe, ENT Service, Hospital Regional de Concepción, Concepción. Professor of Oral and Maxillofacial Radiology, Universidad de Concepción, School of Dentistry, Concepción, Chile. ** Physician Pathologist, Pathology Department, Hospital Regional de Concepción, Chile

*** Professor of Oral and Maxillofacial Radiology, University of North Carolina School of Dentistry, Chapel Hill, USA.
} 
polymorphism, high mitotic activity and necrosis. Lowgrade tumors are highly differentiated, and consist predominantly of muco-secretory cells, with minimal atypia and cystic formation. Intermediate grade lesions consist of a mixture of both cell types (squamous and muco-secretory) (Magliulo \& Appiani; Emerick et al., 2007). The histological subdivision of MEC includes high, intermediate and low-grades, and is highly correlated to the prognostic outcome (Guzzo et al., 2002).

When an infiltrative neoplasm is suspected, MRI (Magnetic Resonance Imaging) with or without intravenous contrast should be performed. MRI has a high sensitivity in determining the extent of the tumor's infiltration pattern, and perineural invasion to the skull base and meningeal membranes (Yousem et al., 2000).

Some investigators have suggested that lowgrade MEC with favorable clinical staging (T1 or T2; N0) can be treated surgically. Surgery and radiotherapy is recommended for high-grade MEC. The treatment is controversial for intermediate MEC; therefore, there is no consensus for treating intermediate MEC. The 5year survival rate is $92 \%$ for low-grade MEC and $63 \%$ for high grade MEC (April et al., 1997). Early cases of MEC involving minor salivary glands have a survival rate of $78,6 \%$ for low-grade and only $50 \%$ for highgrade. The recurrence rate in low grade MEC is very low, unlike for intermediate and high-grade MEC where it reaches $30 \%$ and $70 \%$ respectively (Rosdeutscher \& Burnette, 2003; Ghosh-Laskar et al.).

\section{CLINICAL CASE}

A 61-year-old male patient presented with a growth of the right palatal region allegedly occurring over the last twenty years. A biopsy was performed, revealing clear cells forming tubules and welldifferentiated squamous cell with low atypia. (Fig. 1A). Immunohistochemistry studies of Vimentin and p63 were both positive (Figs. 1B and 1C). It was concluded that both fibrous and bone tissue were infiltrated by Low-Grade MEC. The head and neck cancer board evaluated the results, and recommended treating the patient with radiation therapy and chemotherapy with re-evaluation after these initial treatments.

Once the treatment was completed, a CT (Computed Tomography) scan of the head, neck and thorax was performed using intravenous contrast. The images demonstrated a poorly differentiated
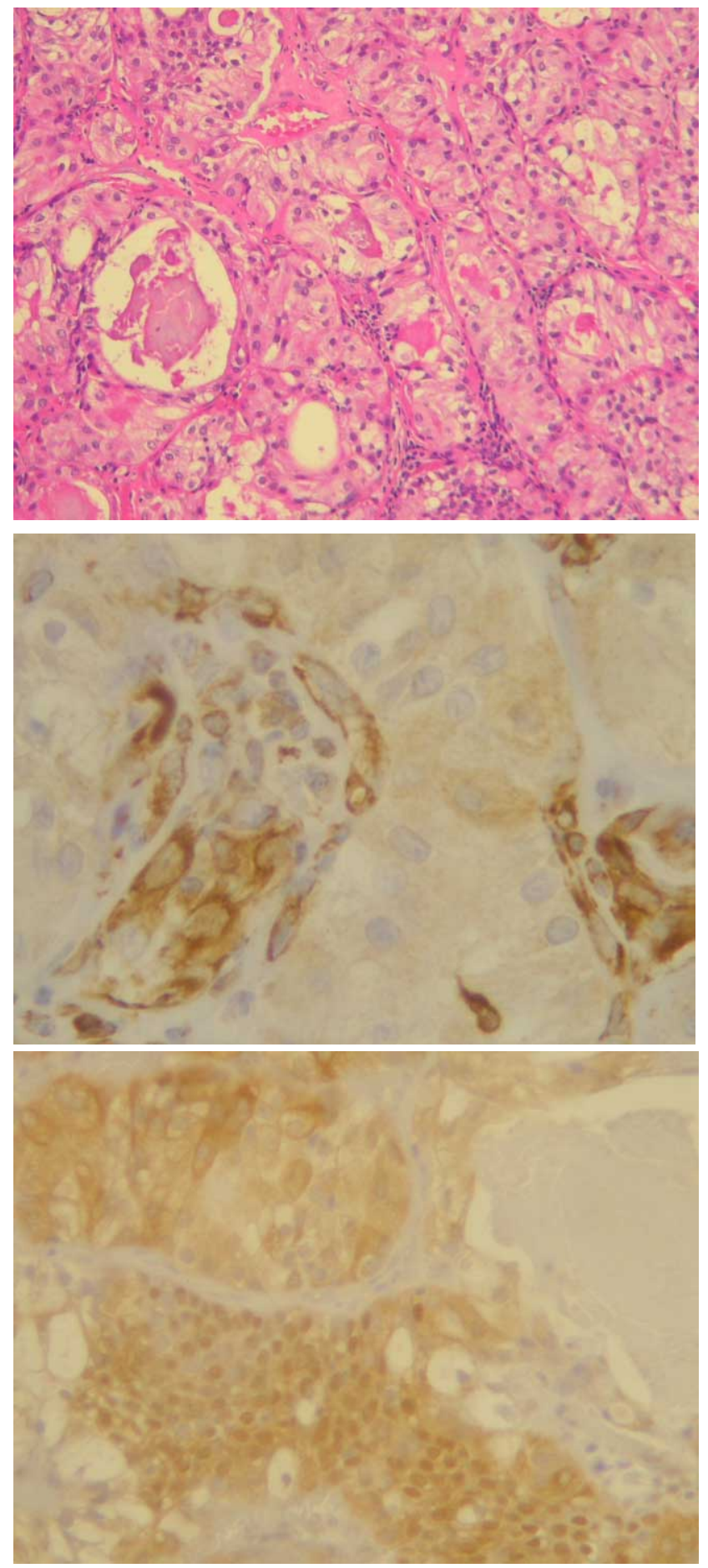

Fig. 1. A: Hematoxyylin \& Eosin Stain tintion: squamous with low atipia. B: Vimentin positive. C: P63 positive.

heterogeneous mass invading the lateral, medial and inferior maxillary sinus walls. The presence of multiple bone fragments suggested destruction of the adjacent bone. (Fig. 2) Adenopathy in the right carotid space was also noted. Uniform enhancement of the mass 


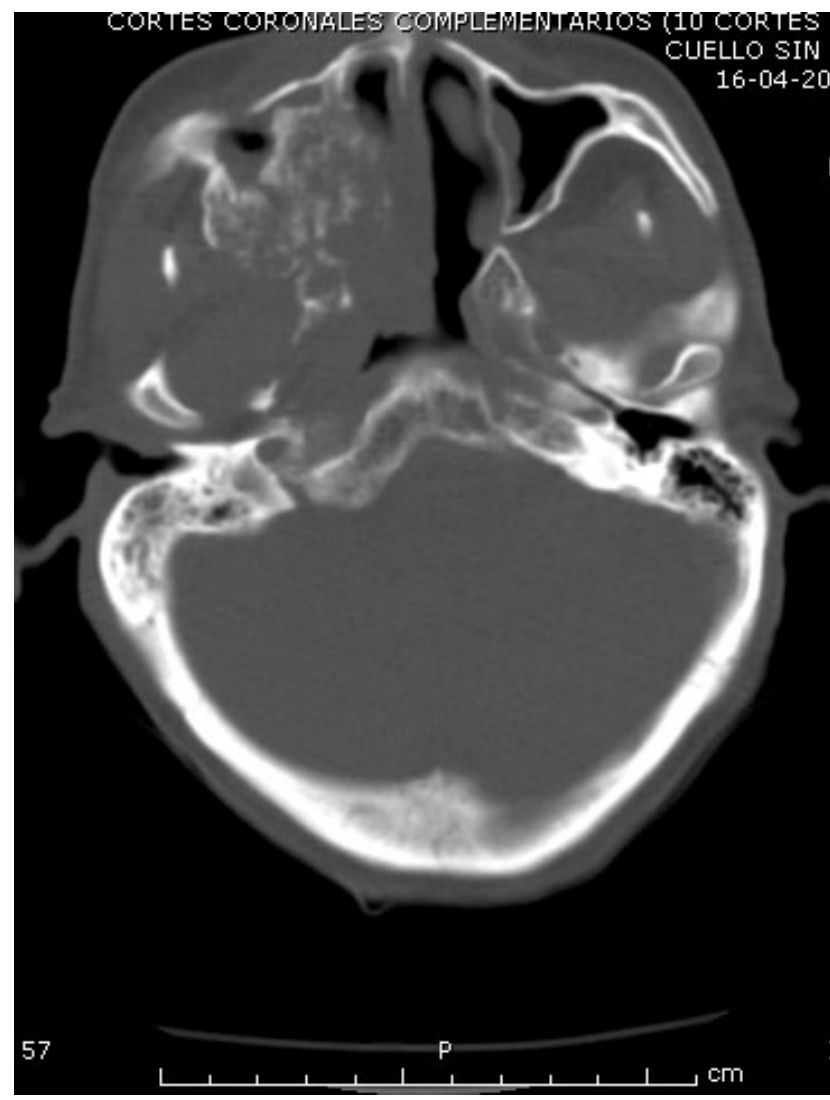

Fig. 2. CT with Bone windows revealing infiltration of lateral, inferior and posterior walls of the right maxillary sinus.

following iodinated contrast media injection suggested involvement of the orbital region. (Figs. 3 and 4) The $\mathrm{CT}$ of the thorax was normal.

T2 weighted MRI images display a uniform mass with high intensity signal; hyper-intense areas are suggestive of cystic or necrotic regions. (Figs. 5 and 6) The post contrast T1 weighted images display a welldifferentiated hetero-geneous mass with well-defined borders within the lesion. There is invasion into the right orbital cavity with extraconal fat infiltration; however, the inferior rectus muscle remains intact. The axial slices demonstrate the medial insertion of the lateral pterygoid muscle. The coronal slices show infiltration of the alveolar bone and hard palate including the nasal septum (Figs. 7 and 8).

Surgical removal of the tumor with reconstruction was recommended but the patient declined and instead opted to enroll in a pain management and palliative care program.

In conclusion, Mucoepidermoid Carcinoma is the most common malignant salivary gland tumor and

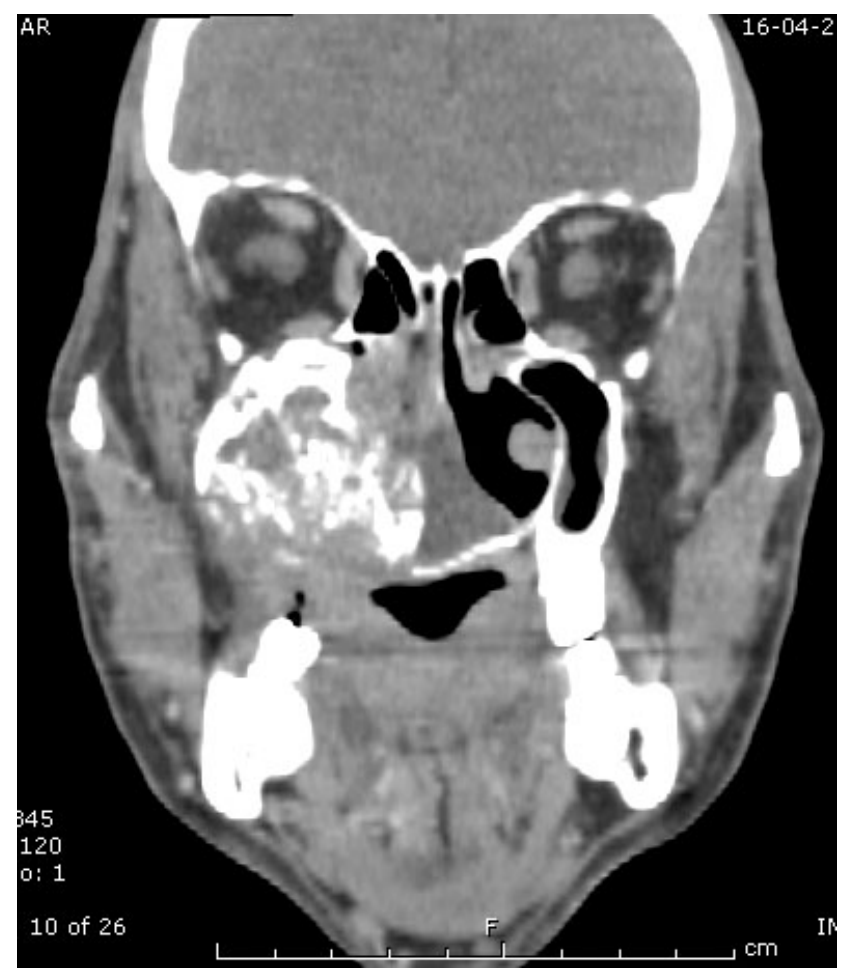

Fig. 3. CT Soft tissues windows CT depicting nasal and palatal involvement.

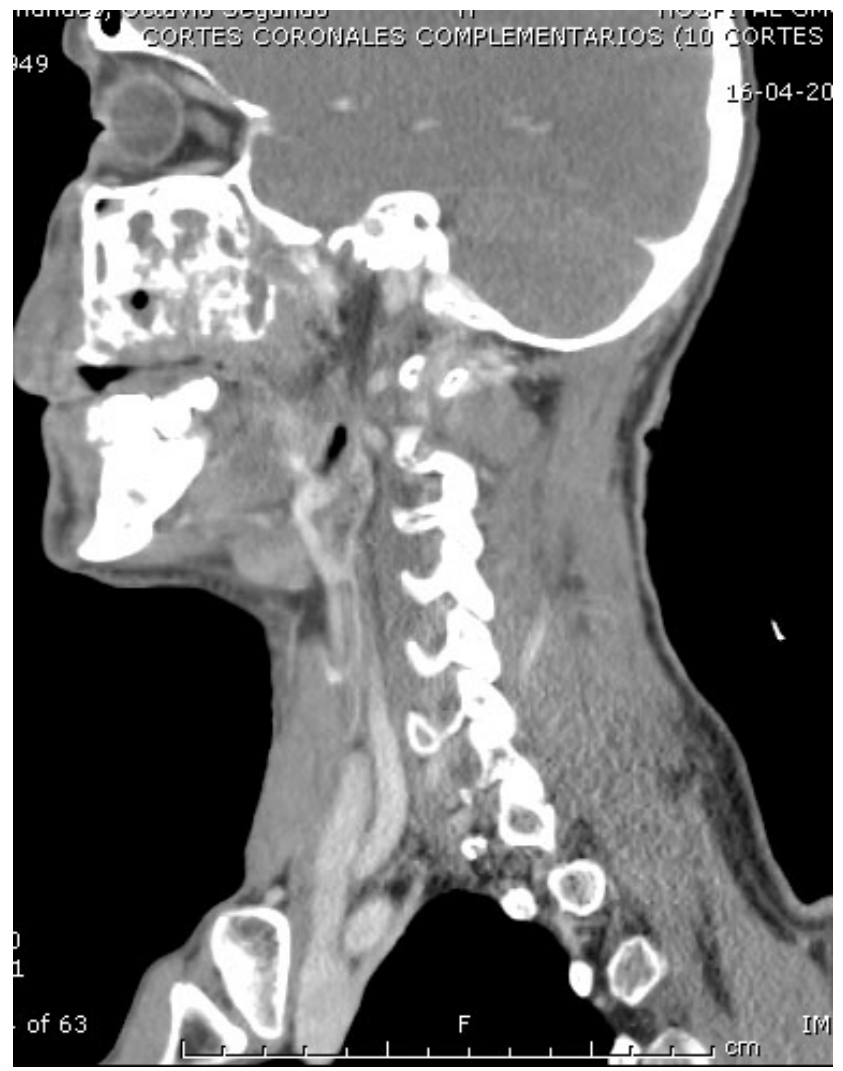

Fig. 4. Post contrast CT showing uniform enhancement and orbital involvement. 


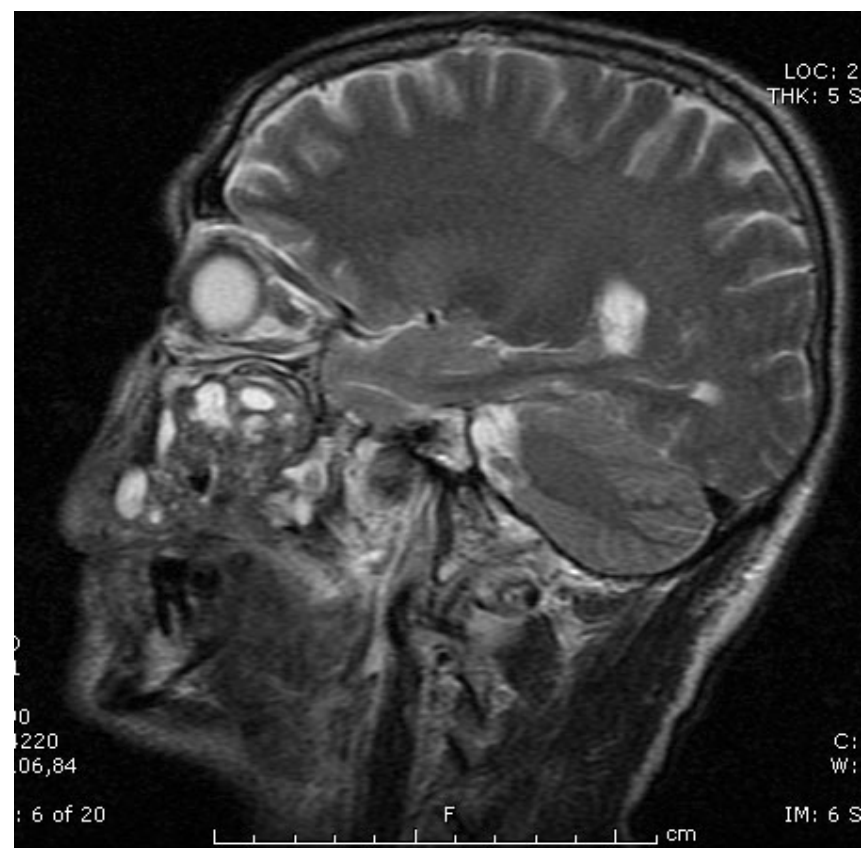

Fig. 5. T2 weighted MRI image showing many hyperintense areas suggestive of cystic or necrotic areas.

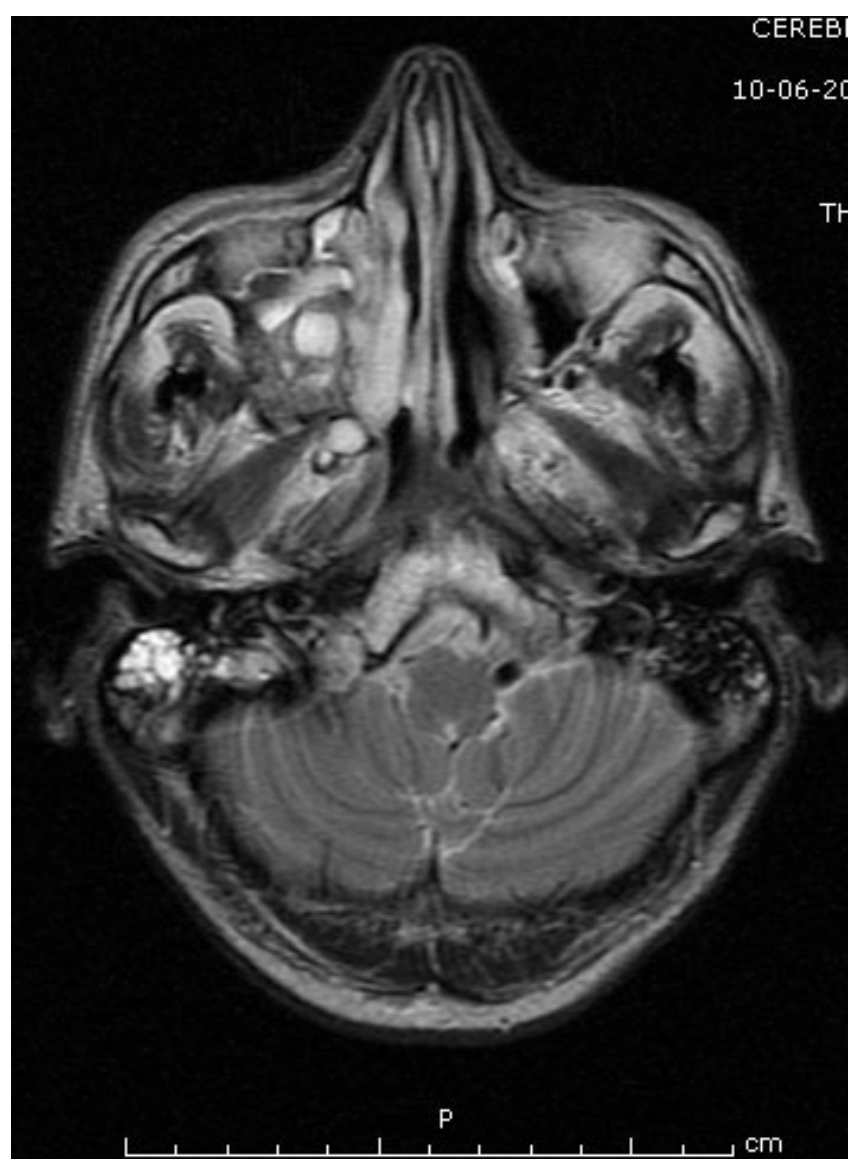

Fig. 6. T2 weighted showing a hyperintense signal in the right mastoid cells. This is an accumulation of secretions due to poor or blocked drainage

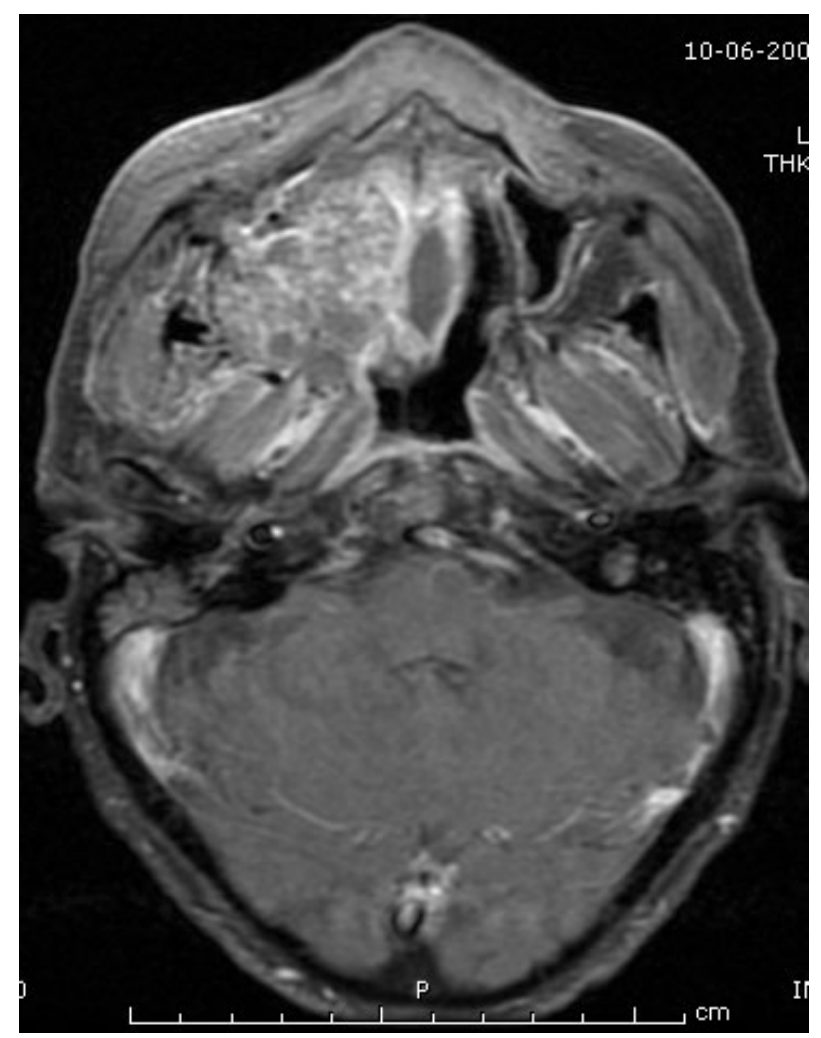

Fig. 7. T1FSGD MRI reveals uniform enhancement enhancement, with medial insertion infiltration to the lateral pterygoid muscle.

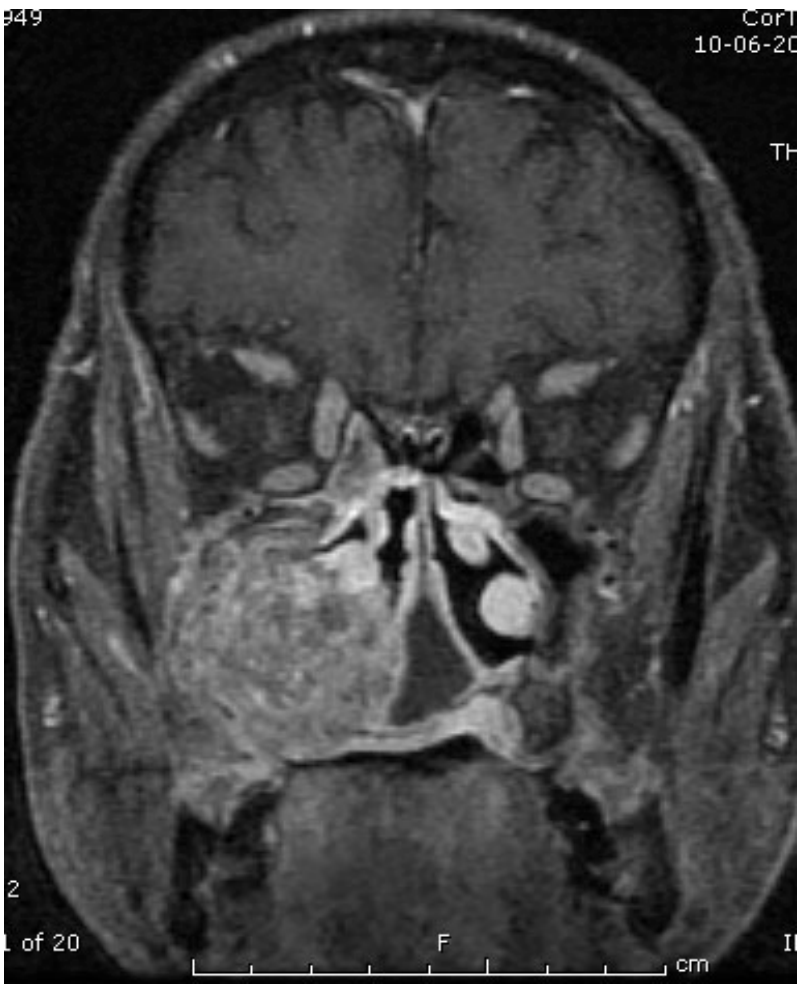

Fig. 8. T1FSGD MRI reveals extraconal fat infiltration, without inferior rectus muscle involvement. 
occurs most frequently in the major salivary glands. MEC's are hisotopathologically subdivided into low, intermediate and high-grade tumors. Its histopathology is highly correlated to the diagnostic outcome. Diagnostic workup should include MRI imaging, with or without intravenous contrast since MRI imaging is highly sensitive indetermining the borders and infiltration patterns, as well as perineural invasion to the skull base and meningeal layers. The standard treatment for low-grade MEC with clinic stage (T1 or T2; N0) is surgical excision. For highgrade tumors, surgery and radiotherapy is recommended. The cure rate after treatment for MEC with minor salivary gland involvement as presented in this case, is $78,6 \%$ for low-grade MEC and $50 \%$ for high-grade MEC.

SEPÚLVEDA, I.; SPENCER, L. \& PLATIN, E. Carcinoma mucoepidermoide nasosinusal: reporte de un caso y revisión de la literatura.Int. J. Odontostomat., 5(3):304-308, 2011.

RESUMEN: Reportamos sobre un paciente que se presentó con un crecimiento del paladar derecho de veinte años de evolución. Se realizó una biopsia del área y se diagnosticó la lesión como carcinoma mucoepidermoide (MEC) bajo grado. Debido al tamaño del tumor, se decidió comenzar el tratamiento con radioterapia seguida de quimioterapia. Una vez que el tratamiento inicial se completó, la lesión fue reevaluada y se recomendo la cirugía seguida de reconstrucción. El paciente rechazó el tratamiento recomendado y optó por seguir un tratamiento de manejo del dolor, programa de cuidados paliativos.

PALABRAS CLAVE: mucoepidermoide, carcinoma, tomografía computarizada, resonancia magnética, tumor sinusal.

\section{REFERENCES}

April, M. M.; Brodsky, L. S.; Cunningham, M. J.; Harari, P. M.; Harrison, L. \& Poje, C. P. Mucoepidermoid carcinoma in a 10-year-old girl. Head Neck, 19:431-5, 1997.

Davies, J. N.; Roberts, D. B.; El-Naggar, A. \& Gillenwater, A. Mucoepidermoid Carcinoma of the Thyroid. Otolaryngol. Head Neck Surg., 133:139, 2005.

Emerick, K. S.; Fabian, R. L. \& Deschler, D. G. Clinical presentation, management, and outcome of high-grade mucoepidermoid carcinoma of the parotid gland. Otolaryngol. Head Neck Surg., 136:783-7, 2007.

Foschini, M. P.; Marucci, G. \& Eusebi, V. Low-grade mucoepidermoid carcinoma of salivary glands: characteristic immunohistochemical profile and evidence of striated duct differentiation. Virchows Arch., 440:53642, 2002.

Gallager, H. S.; Miller, G. V. \& Grampa, G. Primary mucoepidermoid carcinoma of the skin; report of a case. Cancer, 12:286-8, 1959.

Giger, R.; Mhawech, P.; Marchal, F.; Lehmann, W. \& Dulguerov, P. Mucoepidermoid carcinoma of Stensen's duct: a case report and review of the literature. Head Neck, 27:829-33, 2005.

Ghosh-Laskar, S.; Murthy, V.; Wadasadawala, T.; Agarwal, J.; Budrukkar, A.; Patil, N.; Kane, S.; Chaukar, D.; Pai, P.; Chaturvedi, P. \& D'Cruz, A. Mucoepidermoid carcinoma of the parotid gland: factors affecting outcome. Head Neck, 33:497-503, 2011.
Gupta, D. \& Kaluskar, S. K. Primary mucoepidermoid tumor of the middle ear and mastoid. Indian J. Otolaryngol., 55:204-5, 2003.

Guzzo, M.; Andreola, S.; Sirizzotti, G. \& Cantu, G. Mucoepidermoid carcinoma of the salivary glands: clinicopathologic review of 108 patients treated at the National Cancer Institute of Milan. Ann. Surg. Oncol., 9:688-95, 2002.

Kim, T. S.; Lee, K. S.; Han, J.; Im, J. G.; Seo, J. B.; Kim, J. S.; Kim, H. Y. \& Han, S. W. Mucoepidermoid carcinoma of the tracheobronchial tree: radiographic and CT findings in 12 patients. Radiology, 212:643-8, 1999.

Magliulo, G. \& Appiani, M. C. Mucoepidermoid carcinoma of the external auditory canal. Otolaryngol. Head Neck Surg., 142:624-5, 2010.

Rosdeutscher, J. D. \& Burnette, R. Nasal mucoepidermoid carcinoma. Otolaryngol. Head Neck Surg., 129:291-2, 2003.

Yousem, D. M.; Kraut, M. A. \& Chalian, A. A. Major salivary gland imaging. Radiology, 216:19-29, 2000.

Correspondence to:

Dr. Ilson Sepúlveda Aguilar

Diagnostic Department, Radiology Area

School of Dentistry, Universidad de Concepción

Avda. Roosevelt 1550

Concepción

CHILE

Email: isepulvedaa@udec.cl

Received: 07-09-2011

Accepted: 17-10-2011 